\title{
Panel Data Analysis of International Trade in West African Sub Region
}

\author{
Yahaya Haruna Umar, Bamanga Muhammad, Udeme Omoren
}

Statistics Department, Faculty of Science, University of Abuja, Abuja, Nigeria

Email address:

Yahaya.umar@uniabuja.edu.ng (Y. H. Umar), yahagumau@gmail.com (Y. H. Umar)

\section{To cite this article:}

Yahaya Haruna Umar, Bamanga Muhammad, Udeme Omoren. Panel Data Analysis of International Trade in West African Sub Region. American Journal of Theoretical and Applied Statistics. Vol. 9, No. 4, 2020, pp. 106-120. doi: 10.11648/j.ajtas.20200904.14

Received: February 2, 2020; Accepted: March 2, 2020; Published: June 4, 2020

\begin{abstract}
West African countries have suffered so much under poor economic growth rate; this issue is largely caused as a result of the poor performance in international trade, which is one of the most essential tools for economic growth. The study investigated the factors influencing international trade in West African Sub region. A Pooled OLS, Fixed Effect Model, and Random Effect Model were adopted to fit the panel regression model for the panel data sets. The study divided the models into three in other to have proper view of factors influencing international trade across West African Sub-region, each model contain the same independent variables and different dependent variables. The result shows that fixed effect model was accurate for the study. Also from the study it was observed that for the first model which use import as dependent variable, gross domestic production, foreign direct investment, and exchange rate are positively significant to import which implies that all the regressor variable influence import across west African sub region positively, while only GDP and FDI are positively significant to export and only FDI is positively significant to trade balance (TB). We therefore conclude that foreign direct investment is the key macro-economic variable that positively influences the policy of international trade across West African over the period of consideration.
\end{abstract}

Keywords: Panel Data, Model, Pooled OLS, West African Sub-region

\section{Introduction}

A country's imports and exports represent a significant share of her gross domestic product (GDP); thus, international trade is correlated to economic growth. In an open economy, development of foreign trade greatly impacts GDP growth. Countries would be limited to goods and services produced within their territories without international trade. International trade is directly related to globalization because increase in trade activities across border is paramount to the globalization process. The globalized nature of an economy enhances its direct participation in the world market consequently leading to market expansion. According to Adam Smith, expansion of a country's market encourages productivity which inevitably leads to economic growth. Trade occurs because of differences across countries in technologies (Ricardian theory), in factor endowments, differences across countries in technologies as well as continuous renewal of existing technologies and their transfer to other countries $[1,2]$.
Quoting from [3, 4] says that country size and scale economies are important determinants of trade [5]. International trade is an integral part of the total developmental effort and national growth of an economy. This is, in fact, a crucial instrument for industrialization while access to foreign exchange is essential for sustained economic development.

West African countries has suffer so much under poor economic growth rate, this issue is largely caused as a result of the poor performance in international trade, which is one of the most essential tools for economic growth. The role of international trade cannot be stamped in developing countries which economic growth is the sole priority. Empirical studies has shown that economic growth provide support for the growth enhancing effect of international trade [6,7]. After controlling for the quality of institutions, the results reveal no significant effect of trade on growth. However, despite the wealth of literature that supports the view that trade enhances economic growth, there are studies that argue that the increase in openness can prevent economic growth $[8,9]$. In 
the last few decades the trend of increasing international trade is followed by the tendency of increased economic growth in the world. It leads to the conclusion that economic growth and foreign trade are positively correlated [10]. Over the past four decades, economists have created a large amount of statistical evidence on the relationship between foreign trade and economic growth. They estimate the coefficients of correlation, coefficients of regression, cointegration test, and perform various other statistical tests to confirm the existence of the relationship between foreign trade and economic growth. But also the empirical evidence does not clearly established whether the foreign trade leads to economic growth or whether it merely follows economic growth.

Though the effect of trade on economic growth have been in the limelight since the existence of trade, it has been observed from literature that foreign direct investment of a country is another factor that affect the economic growth of a country. Foreign direct investment (FDI) is a major component of capital flow for developing countries, its contribution towards economic growth is widely argued, but most researchers concur that the benefits outweigh its cost on the economy. [11].

FDI embodies a package of potential growth enhancing attributes such as technology and access to international market, but the host country must satisfy certain preconditions in order to absorb and retain these benefits and not all emerging markets possess such qualities. [12, 13, 14]. It has also been observed that a country can enhance its economic growth by freeing up its international trade but the presence of significant institutional issues on the side of imports hinders this from being achieved. Most countries can increase imports quite quickly once trade liberalization occurs, given suitable payment arrangements and an increase in the effective demand for imports. To maintain an acceptable or manageable trade balance, exports must also increase, and this is where many countries encounter some serious practical difficulties and barriers [15]. On the contrary, it was discoveredthat the rule of law is a measure of institution and ratio of trade to GDP on cross-country level of one hundred and sixty-eight (168) for the average of the time frame of 2000-2001 [16]. The authors found out that changes in trade and changes in institutional quality had a substantial positive effect of trade on growth suggesting that trade and institutions jointly affect growth. Recent studies has been carried out on how international trade of a countries and how other factors also influence economic growth, but most of the study have been limited to cross-sectional and time series data set. Therefore, this study attempt to fill the gap identified in the literature review, by carrying out the study with panel data set, and also conducting series of econometric and diagnostics test on the data as well as the model. The study interest also covers estimation of panel regression model with different estimation technique and assesses their performance, for valid measurement of relationship between the independent variables and independent variables.
The main aim of this study is to investigate the factors influencing international trade in West African Sub region and the specific objectives of the study are to examine the factors influencing international trade flow across West African Sub region and to estimate the panel regression model for the international trade under different estimation technique

\section{Data}

The data for this study were obtain from a secondary source [10]. The data set on GDP, GDP per capital and Total Land area, and international trade (export, import, and balance of trade) and foreign direct investment were found at Merchandise trade by partner and product, website http://unctadstat.unctad.org/ReportFolders/reportFolders.aspx which covers some selected West African countries for the period of 2000-2017. The study adopts panel regression analysis approach. This pooled data analysis combining cross-sectional and time series data which enables us to concurrently estimate differences across countries as well as over time. Typically, panel data regression has three kinds of models: pooled ordinary least square model (POLS), fixedeffects model (FEM), and random-effects model (REM).

\section{Method}

Panel data models use in this study examine group (individual-specific) effects, time effects, or both in order to deal with heterogeneity or individual effect that may or may not be observed. These effects are either fixed or random effect. A fixed effect model examines if intercepts vary across group or time period, whereas a random effect model explores differences in error variance components across individual or time period.

The panel data econometric methods used is to estimate the possible various specifications of our models: pooled ordinary least squares (POLS), Least Square Dummy Variable (LSDV), within effect estimation, and GLS

\subsection{Pooled Ordinary Least Square (POLS)}

The class of models that can be estimated using a pooled ordinary least squares estimator can be written as follows:

$$
Y_{i t}=\alpha+\beta x_{i t}^{\iota}+\varepsilon_{i t} i=1,2, \ldots . N ; t=1,2, \ldots T
$$

Where $Y_{i t}$ is the dependent variable, $x_{i t}$ are the $\mathrm{k}$ regressor (excluding the intercept terms), $\beta$ is the regressor coefficient, and $\varepsilon_{i t}$ is the reminder disturbance, in our model below the dependent variables are export, import, and trade of balance with the same independent variables. Therefore we have three models to estimates, which are specified below.

The econometric model with natural log of Import as the dependent variable in the model is specified as:

$$
\operatorname{lnImp} p_{i, t}=\alpha+\beta_{1} \operatorname{lng} d p_{i, t}+\beta_{2} \operatorname{lnexr}_{i, t}+\beta_{3} \ln f d i_{i, t}+\varepsilon_{i, t}
$$

Where $i$ indicates the countries included in the analysis, $t$ 
denotes the time period (2000-2017), the dependent variable is the natural log of import of the countries $i$ under the study at year $\mathrm{t}, \beta_{0}$ is intercept of the model and $\beta_{1}, \beta_{2}, \ldots, \beta_{3}$ are corresponding coefficient to be estimated of the independent variables:

Lngdp: Natural log of gross domestic production,

Lnfdi: Natural log of foreign direct investment

Lnexr: Natural log of exchange rate

The econometric model with natural log of export as the dependent variable in the model is specified as:

$$
\ln \exp _{i, t}=\alpha+\beta_{1} \operatorname{lng} d p_{i, t}+\beta_{2} \ln \operatorname{exr}_{i, t}+\beta_{3} \ln f d i_{i, t}+\varepsilon_{i, t}
$$

Where $\ln \exp _{i, t}$ is the natural log export of the countries iunder the study at time $t$.

Similarly, the model for the trade balance as the dependent variable was also developed given by $(\operatorname{Imp}-\exp )$ in value and it is specified as:

$$
\ln t b_{i, t}=\alpha+\beta_{1} \operatorname{lng} d p_{i, t}+\beta_{2} \operatorname{lnexr}_{i, t}+\beta_{3} \ln f d i_{i, t}+\varepsilon_{i, t}
$$

\subsection{Ordinary Least Square Assumptions}

1. Linearity says that the dependent variable is formulated as a linear function of a set of independent variable and the error (disturbance) term.

2. Exogeneity: says that the expected value of disturbances is zero or disturbances are not correlated with any regressors.

3. Disturbances have the same variance (3.a homoskedasticity) and are not related with one another (3.b nonautocorrelation)

4. The observations on the independent variable are not stochastic but fixed in repeated samples without measurement errors.

5. Full rank assumption says that there is no exact linear relationship among independent variables (no multicollinearity).

\subsection{Fixed Effect and Random Effect Model}

Panel data models examine fixed and/or random effects of individual or time. The core difference between fixed and random effect models lies in the role of dummy variables. A parameter estimate of a dummy variable is a part of the intercept in a fixed effect model and an error component in a random effect model. Slopes remain the same across group or time period in either fixed or random effect model. The functional forms of one-way fixed and random effect models are:

Fixed Effect Model: $y_{i t}=\left(\alpha+u_{i}\right)+X_{i t}^{i} \beta+v_{i t}$

Random Effect Model: $y_{i t}=\alpha+X^{\iota}{ }_{i t} \beta+\left(u_{i}+v_{i t}\right)$.

Where $u_{i}$ fixed or random effect is is specific to individual (group) or time period that is not included in the regression, and errors are independent identically distributed, $v_{i t} \sim \operatorname{IID}\left(0, \sigma_{v}^{2}\right)$

A fixed group effect model examines individual differences in intercepts, assuming the same slopes and constant variance across individual (group and entity). Since an individual specific effect is time invariant and considered a part of the intercept, $i u$ is allowed to be correlated with other regressors; That is, OLS assumption 2 is not violated. This fixed effect model is estimated by least squares dummy variable (LSDV) regression (OLS with a set of dummies) and within effect estimation methods.

A random effect model assumes that individual effect (heterogeneity) is not correlated with any regressor and then estimates error variance specific to groups (or times). Hence, $u_{i}$ is an individual specific random heterogeneity or a component of the composite error term. This is why a random effect model is also called an error component model. The intercept and slopes of regressors are the same across individual. The difference among individuals (or time periods) lies in their individual specific errors, not in their intercepts.

A random effect model is estimated by generalized least squares (GLS) when a covariance structure of an individual $i$, $\Sigma$ (sigma), is known. The feasible generalized least squares (FGLS) or estimated generalized least squares (EGLS) method is used to estimate the entire variance-covariance matrix $\mathrm{V}(\Sigma$ in all diagonal elements and 0 in all off-diagonal elements) when $\Sigma$ is not known. There are various estimation methods for FGLS including the maximum likelihood method and simulation [17].

A random effect model reduces the number of parameters to be estimated but will produce inconsistent estimates when individual specific random effect is correlated with regressors [18]. Fixed effects are tested by the F test, while random effects are examined by the Lagrange multiplier (LM) test [19]. If the null hypothesis is not rejected in either test, the pooled OLS regression is favored. The Hausman specification test [20] compares a random effect model to its fixed counterpart. If the null hypothesis that the individual effects are uncorrelated with the other regressors is not rejected, a random effect model is favored over its fixed counterpart.

\subsubsection{Estimating a Fixed Effect Model}

There are several strategies for estimating a fixed effect model. The least squares dummyvariablemodel (LSDV) uses dummy variables, whereas the "within" estimation does not.

These strategies, of course, produce the identical parameter estimates of regressors (non-dummy independent variables). The "between" estimationfits a model using individual or time means of dependent and independent variables without dummies.

LSDV with a dummy dropped out of a set of dummies is widely used because it is relatively easy to estimate and interpret substantively. This LSDV, however, becomes problematic when there are many individuals (or groups) in panel data. If $T$ is fixed and $n \rightarrow \infty$ ( $n$ is the number of groups or firms and $T$ is the number of time periods), parameter estimates of regressors are consistent but the coefficients of individual effects, $\propto+u_{i}$ are not [21]. In this short panel, LSDV includes a large number of dummy variables; the number of these parameters to be estimatedas $n$ increases (incidental parameter problem); therefore, LSDV loses $n$ degrees of freedom but returns less efficient estimators. Under this circumstance, LSDV is useless and thus calls for another strategy, the within effect estimation. 
Unlike LSDV, the "within" estimation does not need dummy variables, but it uses deviations from group (or time period) means. That is, "within" estimation uses variation within each individual or entity instead of a large number of dummies. The "within" estimation is,

$$
\left(y_{i t}-\underline{y_{i}}\right)=\left(x_{i t}-\underline{x}_{i}\right)^{i} \beta+\left(\varepsilon_{i t}-\underline{\varepsilon}_{i}\right),
$$

Where $\underline{y}_{i}$ is the mean of dependent variable (DV) of the individual (group) $i, \underline{x}_{i}$ represent the means of independent variables (IVs) of group $i$, and $\varepsilon_{i}$ is the mean of errors of group $i$ parameter estimates of regressors in the "within" estimation are identical to those of LSDV.

The "within" estimation reports correct the sum ofsquarederrors (SSE). The "within" estimation, however, has several disadvantages.

First, data transformation for "within" estimation wipes out all time-invariant variables (e.g., gender, citizenship, and ethnic group) that do not vary within an entity [22]. Since deviations of time-invariant variables from their average are all zero, it is not possible to fit LSDV when a model has time-invariant independent variables.

Second, "within" estimation produces incorrect statistics. Since no dummy is used, the within

Effect model has larger degrees of freedom for errors, accordingly reporting small mean squared errors (MSE), standard errors of the estimates (SEE) or square root of mean squared errors (SRMSE), and incorrect (smaller) standard errors of parameter estimates.

Third, $R^{2}$ of "within" estimation is not correct because the intercept term is suppressed. Finally, the "within" estimation does not report dummy coefficients.

\subsubsection{Estimating Random Effect Models}

The one-way random effect model incorporates a composite error term, $w_{i t}=u_{i}+v_{i t}$. The $u_{i}$ are assumed independent of traditional error term $v_{i t}$ and regressors $X_{i t}$, which are alsoindependent of each other for all iand $t$. Remember that this assumption is not necessary in afixed effect model. This model is,

$$
y_{i t}=\alpha+X^{\iota}{ }_{i t} \beta+u_{i}+v_{i t}, \text { where } u_{i} \sim I I D\left(0, \sigma^{2}{ }_{u}\right), \text { and } v_{i t} \sim \operatorname{IID}\left(0, \sigma_{v}^{2}\right)
$$

The covariance elements of

$$
\begin{gathered}
\operatorname{cov}\left(w_{i t}, w_{j s}\right)=E\left(w_{i t}, w^{i}{ }_{j s}\right) \text { are } \sigma_{u}^{2}+\sigma^{2}{ }_{v} \text { if } i=j \text { and } t=s \text { and } \sigma_{u}^{2} \text { if } i= \\
j \text { and } t \neq s \text {. therefore, the covariance structure of composite errors } \Sigma=E\left(w_{i}, w_{t}\right)
\end{gathered}
$$

for individual $\mathrm{i}$ and the variance-covariance matrix of entire disturbance (errors) $\mathrm{V}$ are,

$$
\sum_{T x T}=\left[\begin{array}{cccc}
\sigma_{u}^{2}+\sigma_{v}^{2} & \sigma_{u}^{2} & \ldots & \sigma_{u}^{2} \\
\sigma_{u}^{2} & \sigma_{u}^{2}+\sigma_{v}^{2} & \ldots & \sigma_{u}^{2} \\
\ldots & \ldots & \ldots & \ldots \\
\sigma_{u}^{2} & \sigma_{u}^{2} & \ldots & \sigma_{u}^{2}+\sigma_{v}^{2}
\end{array}\right] \text { and } V_{n T X n T}=I_{n} \oplus \Sigma=\left[\begin{array}{cccc}
\Sigma & 0 & \ldots & 0 \\
0 & \Sigma & \ldots & 0 \\
\ldots & \ldots & \ldots & \ldots \\
0 & 0 & \ldots & \Sigma
\end{array}\right]
$$

A random effect model is estimated by generalized least squares (GLS) when the covariance structure is known, and by feasible generalized least squares (FGLS) or estimated generalized least squares (EGLS) when the covariance structure of composite errors is unknown. Since $\Sigma$ is often unknown, FGLS/EGLS is more frequently used than GLS. Compared to a fixed effect counterpart, a random effect model is relatively difficult to estimate.

In FGLS, you first have to estimate $\theta$ using $\widehat{\sigma}_{u}^{2}$ and $\widehat{\sigma}_{v}^{2}$. The $\widehat{\sigma}_{u}^{2}$ comes from the between effect estimation (group mean regression) and $\widehat{\sigma}_{v}^{2}$. is derived from the SSE (sum of squared errors) of the within effect estimation or the deviations of residuals from group means of residuals.

$$
\begin{gathered}
\hat{\theta}=1-\sqrt{\frac{\hat{\sigma}_{u}^{2}}{T \hat{\sigma}_{u}^{2}+\hat{\sigma}_{v}^{2}}}=1-\sqrt{\frac{\hat{\sigma}_{u}^{2}}{T \hat{\sigma}_{\text {between }}^{2}}}, \\
\text { where } \hat{\sigma}_{u}^{2}=\hat{\sigma}_{\text {between }}^{2}-\frac{\hat{\sigma}_{v}^{2}}{T} \\
\text { where } \hat{\sigma}_{\text {between }}^{2}=\frac{S S E_{\text {between }}}{n-k-1} \\
\hat{\sigma}_{v}^{2}=\frac{S S E_{\text {within }}}{n T-n-k}=\frac{e^{\prime} e_{\text {within }}}{n T-n-k}
\end{gathered}
$$

$$
\hat{\sigma}_{v}^{2}=\frac{\sum_{i=1}^{n} \sum_{i=1}^{T}\left(v_{i t}-\bar{v}_{i} \cdot\right)^{2}}{n T-n-k}
$$

where $v_{i t}$ are the residual of the LSDV

Then, the dependent variable, independent variables, and the intercept term need to be transformed as follows,

$$
\begin{gathered}
y_{i t}^{*}=y_{i t}-\hat{\theta} \underline{y}_{i *} \\
x_{i t}^{*}=x_{i t}-\hat{\theta} \underline{x}_{i *} \text { for all } x_{k} \\
\alpha^{*}=1-\hat{\theta}
\end{gathered}
$$

Finally, run OLS on those transformed variables with the traditional intercept suppressed.

$$
y_{i t}^{*}=\alpha^{*}+x_{i t}^{*} \beta^{*}+\varepsilon_{i t}^{*} .
$$

\subsection{Testing Fixed and Random Effects}

How do we know if fixed and/or random effects exist in panel data in hand? A fixed effect is tested by F-test, while a random effect is examined by [19] Lagrange multiplier (LM) test. The former compares a fixed effect model and OLS to 
see how much the fixed effect model can improve the goodness-of-fit, whereas the latter contrast a random effect model with OLS. The similarity between random and fixed effect estimators is tested by a Hausman test.

\subsubsection{F-test for Fixed Effects}

In a regression of $y_{i t}=\alpha+\mu_{i}+X^{i}{ }_{i t} \beta+\varepsilon_{i t}$, the null hypothesis is that all dummy parameters except for one for the dropped are all zero, $H_{0}: \mu_{1}=\cdots=\cdots=\mu_{n-1}$. The alternative hypothesis is that at least one dummy parameter is not zero. This hypothesis is tested by an F test, which is based on loss of goodness-of-fit. This test contrasts LSDV (robust model) with the pooled OLS (efficient model) and examines the extent that the goodness-of-fit measures (SSE or $\mathrm{R}^{2}$ ) changed.

$$
\begin{gathered}
F(n-1, n t-n-k)=\frac{\left(e^{\prime} e_{\text {pooled }-} e^{\prime} e_{L S D V}\right) /(n-1)}{\left(e^{\prime} e_{L S D V}\right) /(n T-n-k)} \\
=\frac{\left(R_{L S D V}^{2}-R_{\text {pooled }}^{2}\right) /(n-1)}{\left(1-R_{L S D V}^{2}\right) /(n T-n-k)}
\end{gathered}
$$

If the null hypothesis is rejected (at least one group/time specific intercept uiis not zero), you may conclude that there is a significant fixed effect or significant increase in goodness-of-fit in the fixed effect model; therefore, the fixed effect model is better than the pooled OLS.

\subsubsection{Breusch-Pagan LM Test for Random Effects}

[19] Lagrange multiplier (LM) test examines if individual (or time) specific variance components are zero, $\mathrm{H}_{0}: \sigma_{u}^{2}=0$. The LM statistic follows the chi-squared distribution with one degree of freedom.

$$
L M_{u}=\frac{n T}{2(T-1)}\left[\frac{T^{2} \bar{e}^{\prime} \bar{e}}{e^{\prime} e}-1\right]^{2} \sim x^{2}(1),
$$

where $\bar{e}$ is the $\mathrm{n} X 1$ vector of the group means of the pooled regression residuals, and e'e is the SSE of the pooled OLS regression.

Baltagi (2001) presents the same LM test in a different way.

$$
\begin{aligned}
& L M_{u}=\frac{n T}{2(T-1)}\left[\frac{\sum\left(\sum e_{i t}\right)^{2}}{\sum \sum e_{i t}^{2}}-1\right]^{2} \\
& =\frac{n T}{2(T-1)}\left[\frac{\sum\left(T \bar{e}_{i .}\right)^{2}}{\sum \sum e_{i t}^{2}}-1\right]^{2} \sim x^{2}(1)
\end{aligned}
$$

If the null hypothesis is rejected, you can conclude that there is a significant random effect in the panel data, and that the random effect model is able to deal with heterogeneity better than does the pooled OLS.

\subsection{Hausman Test for Comparing Fixed and Random Effects}

Hausman specification test compares fixed and random effect models under the null hypothesis that individual effects are uncorrelated with any regressor in the model [20]. If the null hypothesis of no correlation is not violated, LSDV and GLS are consistent, but LSDV is inefficient; otherwise, LSDV is consistent but GLS is inconsistent and biased [18]. The estimates of LSDV and GLS should not differ systematically under the null hypothesis. The Hausman test uses that "the covariance of an efficient estimator with its difference from an inefficient estimator is zero" [18].

$$
L M=\left(b_{L S D V}-b_{\text {random }}\right) \widehat{W}^{-1}\left(b_{L S D V}-b_{\text {random }}\right) \sim \chi^{2}(k)
$$
$\underset{\operatorname{Where}}{\operatorname{Var}\left(b_{\text {random }}\right)} \widehat{W}=\operatorname{Var}\left(b_{L S D V}-b_{\text {random }}\right)=\operatorname{Var}\left(b_{L S D V}\right)-$

is the difference in the estimated covariance matrices of LSDV (robust model) and GLS (efficient model). Keep in mind that an intercept and dummy variables SHOULD be excluded in computation. This test statistic follows the chisquared distribution with $k$ degrees of freedom.

The formula says that a Hausman test examines if "the random effects estimate is insignificantly different from the unbiased fixed effect estimate" [22]. If the null hypothesis of no correlation is rejected, you may conclude that individual effects uiare significantly correlated with at least one regressors in the model and thus the random effect model is problematic. Therefore, you need to go for a fixed effect model rather than the random effect counterpart. A drawback of this Hausman test is, however, that the difference of covariance matrices $W$ may not be positive definite; Then, we may conclude that the null is not rejected assuming similarity of the covariance matrices renders such a problem [18].

\section{Statistical Data Analysis and Discussion}

This section presents the statistical analysis of our findings. Preliminary data analysis is performed before the actual statistical data analysis. Firstly, it is important to quantify the behavior of a random variable. The preliminary analysis considered in this study comprises of computation of basic descriptive statistics (mean, standard deviation, maximum, and minimum), the correlation between the variables across the panels and the time variants, and finally the visibility of the variables through the line plot with respect to each panels and the time series.

Table 1. Descriptive Analysis Result.

\begin{tabular}{llllll}
\hline Variables & Mean & Std. Dev. & Min & Max & Observ. \\
\hline EXPRT & & & & & \\
Overall & 8662.788 & 19580.57 & 65.88 & 102438.1 & 187 \\
Between & & 19137.66 & 148.6 & 65466.44 & 11 \\
Within & & 6975.253 & -24691.59 & 45634.43 & 17 \\
IMP & & & & & \\
Overall & \multirow{2}{*}{421.91} & 16257.93 & 87.16 & 90794.19 & 187 \\
Between & & 15289.59 & 216.2541 & 53158.41 & 11 \\
Within & & 7117.448 & -18614.94 & 46057.69 & 17 \\
TB & & & & & \\
Overall & 239.5443 & 5734.016 & -233381.14 & 24653.61 & 187 \\
Between & & 4215.917 & -3656.561 & 12308.03 & 11 \\
Within & & 4078.41 & -35449.63 & 12585.12 & 17 \\
\hline
\end{tabular}




\begin{tabular}{llllll}
\hline Variables & Mean & Std. Dev. & Min & Max & Observ. \\
\hline FDI & & & & & \\
Overall & 776.7852 & 1612.183 & 0.4 & 8914.89 & 187 \\
Between & & 1410.024 & 14.10118 & 4808.42 & 11 \\
Within & & 884.3019 & -2754.215 & 4883.255 & 17 \\
GDP & & & & & \\
Overall & 103534.5 & 764576.2 & 97.28 & 6073570 & 187 \\
Between & & 336663.7 & 102.6771 & 1118496 & 11 \\
Within & & 693530.2 & -1003309 & 5058608 & 17 \\
EXR & & & & & \\
Overall & 99.55587 & 21.17056 & 55.99322 & 197.4474 & 187 \\
Between & & 17.06818 & 61.32514 & 131.5649 & 11 \\
Within & & 13.48815 & 56.91 & 181.1258 & 17 \\
\hline
\end{tabular}

Sources: Author's Computation Using STATA 11.0

In table 1, the descriptive statistics of the macro-economic variables under consideration were analyzed, the variables include in the international trade and gross domestic production of West African sub region over the period of 16 years. It was observed that EXPRT in West African sub region over the last 16 years is on the average 8662.788 with the overall standard deviation of 19580.57 which implies wide deviation of the data set form the central tendency, between the country in absence of the period pigged 19137.66 which also give the same interpretation with the overall standard deviation this both contrary the standard deviation within the period of 16 years regardless of the countries which exhibit low dispersion from central tendency with 6975.253. The overall minimum and maximum value for the variable EXPRT are 65.88 and 102438.1.

The overall average value for variable IMP across the West African countries for the observed period in the study is 8421.91 , with overall standard deviation of 16257.93 which display wide dispersion, also the standard deviation between the west African countries regardless of the period exhibit the same pattern of wide dispersion from the central value with value 15289.59 , the standard deviation within the time frame from the study exhibit a different pattern with low dispersion value of 7117.448. 87.16 and 90794.19 represent the overall minimum and maximum value of the variable IMP.

Variable TB of the West African countries with the period of 16 years has the mean value of 239.5443 , with overall standard deviation 5734.016 which is higher than the mean value, this implies wide departure of the data set of variable TB from the central tendency value, the standard deviation (4215.917) between the countries data set for the variable was also high in compare to the mean value of the variable which measure the same degree of dispersion as of the overall, the same thing also goes for the within period standard deviation (4078.41) the variable has the overall minimum and maximum value of (-233381.14 and 24653.61).

The average overall value for FDI across the 10 West African countries considered in this study within the period of 16 years is 776.7852 with the overall standard deviation of 1612.183 that measure the dispersion degree of the data set, the between and within standard deviation are 1410.024 and 884.3019 which are higher than the mean value of the variable, the variable has 0.4 and 8914.89 minimum and maximum value.

And finally GDP has the overall mean of 103534.5 across the countries under the study within the duration considered, with overall standard deviation of 764576.2 higher than the mean value which implies wide dispersion of data set from the central value, also the within period and between panels standard deviation (336663.7 and 693530.2) exhibit the same thing with the overall standard deviation. The overall minimum and maximum value of the variable are 97.28 and 6073570.

The overall average value for variable EXR across the West African countries for the observed period in the study is 99.55587, with overall standard deviation of 21.17056 which display low dispersion in compare with the mean value, also the standard deviation between the west African countries regardless of the period exhibit the same pattern of low dispersion from the central value with value 17.06818, the standard deviation within the time frame from the study exhibit also the same pattern of low dispersion value of 13.48815. the overall minimum and maximum value of the variable EXR are 55.99322 and 197.4474.

Table 2. Correlation Matrix Analysis.

\begin{tabular}{lllllll}
\hline & GDP & IMP & EXP & FDI & TB & EXR \\
\hline GPD & 1.000 & & & & & \\
IMP & 0.5938 & 1.000 & & & & \\
EXP & 0.9657 & 0.3392 & 1.000 & & & \\
FDI & 0.2828 & 0.8974 & 0.8992 & 1.000 & & \\
TB & -0.2416 & 0.4624 & 0.6768 & 0.5262 & 1.000 & \\
EXR & 0.0811 & 0.0791 & 0.0646 & 0.0414 & -0.0036 & 1.000 \\
\hline
\end{tabular}

Sources: Author's Computation using STATA version 11

Table 2 presents the correlation matrix analysis of the variable in the study, it was notice from the table that correlation between the independent variables were low and correlation between the independent variables and the dependent variable were high, strong positive relationship (0.9657) exist between GDP and EXP of the countries under the study, this implies that increase in gross domestic production will automatically increase the exportation of the countries. The same thing goes with the relationship between FDI and EXP (0.8992) which also display high degree of relationship between the two variables across the countries within the period speculated. Also a normal positive relationship exist between the GDP and IMP of the value (0.5938) which implies that increase in the gross domestic production of the countries give importation the chances of increasing and lastly there exist negative correlation between the GDP and TB which implies that increase in GDP will automatically lead to decrease in the trade balance, this seems a bit unfair under international trade policy. 


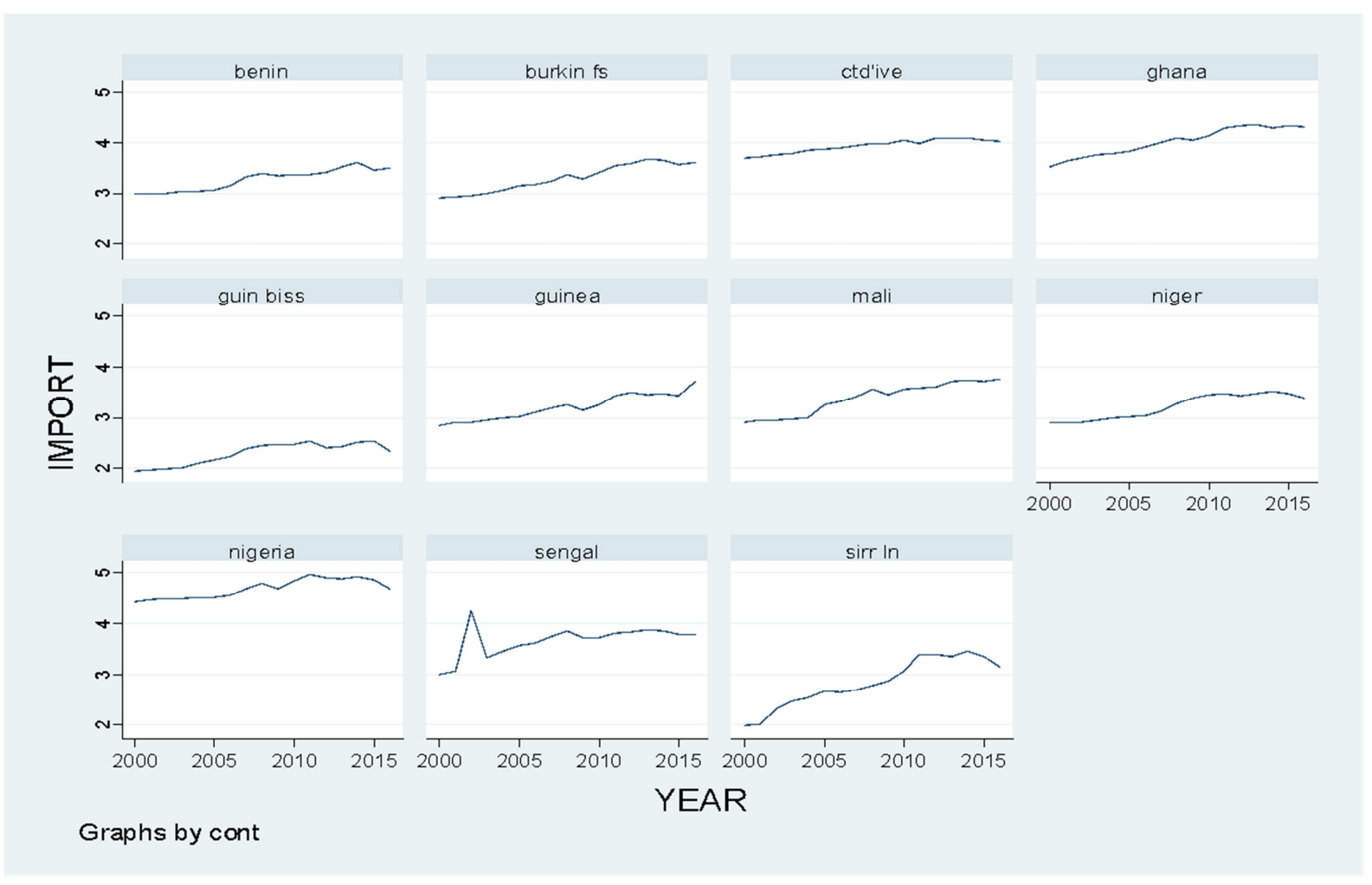

Figure 1. Panel Data line plot for Import variable.

The figure 1 display the panels' plot of the variable import for individual country under the study within the time series range from 2000-2006, it was observe from the plot that most of the countries in the plot exhibit an upward tendency, which implies the high importations of goods in the individual country over the period speculated.

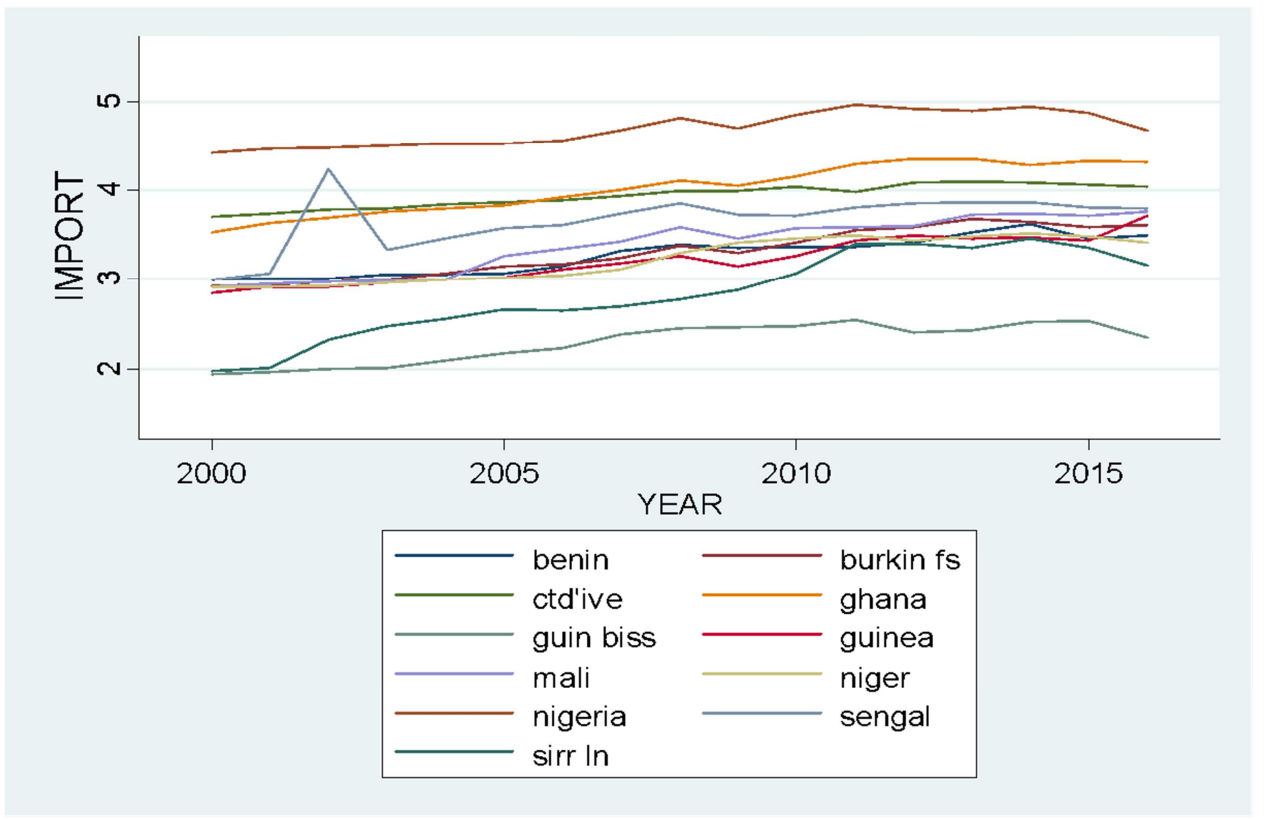

Figure 2. Overlay panel plot for import.

Figure 2 display the panels plot of the countries importation within the time frame for the study, the plot marge and compare the importation of the countries, it was observed that Burkin $\mathrm{Na}$ faso has the highest importation, and also Nigeria experience high importation policy during the year 2000 to 2005 before it come down, other countries follow slightly the same pattern. 


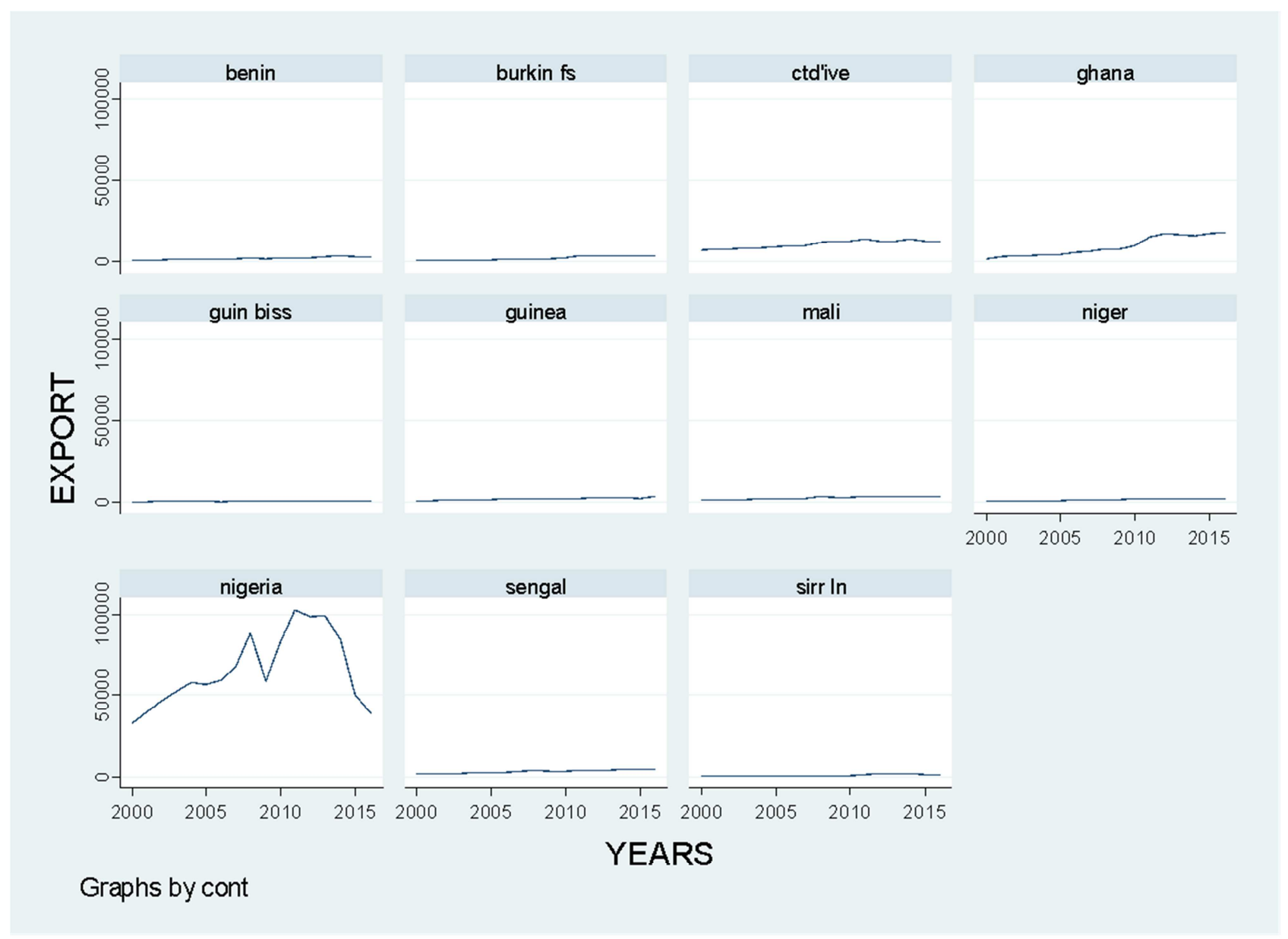

Figure 3. Panel Data line plot for Export variable.

The figure 3 display the panels plot of the variable export for individual country under the time frame, it was observed from the plot that most of all the countries under the study exhibit a flat and constant movement over the years, it implies that most of the countries in West African sub region did not engage much in exportation, while Nigeria exhibit trend pattern also Ghana and coted'ive display slight upward movement.

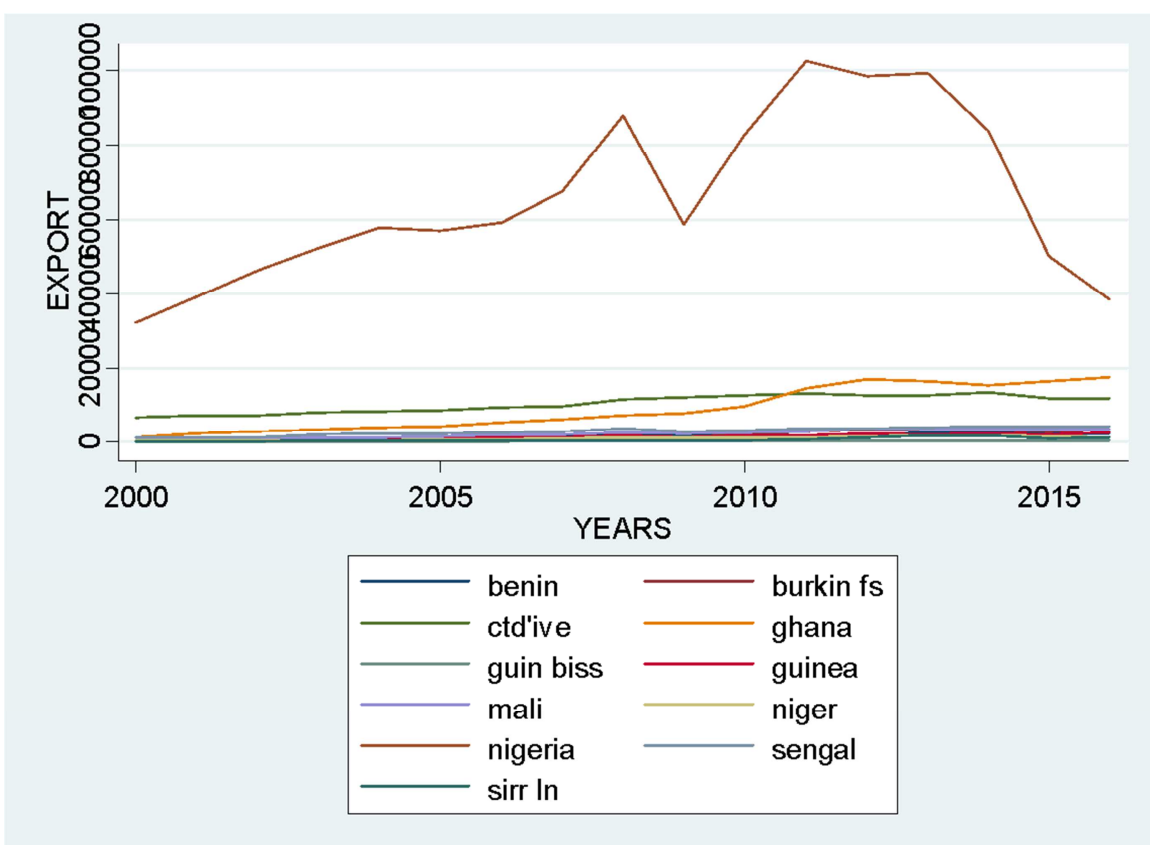

Figure 4. Overlay panel plot for Export. 
Figure 4 display the panels plot of the countries importation within the time frame for the study, the plot marge and compare the exportation of the countries, it was observed from the plot that Nigeria has the highest involvement of exportation in compare with is counterpart in West African Sub region.

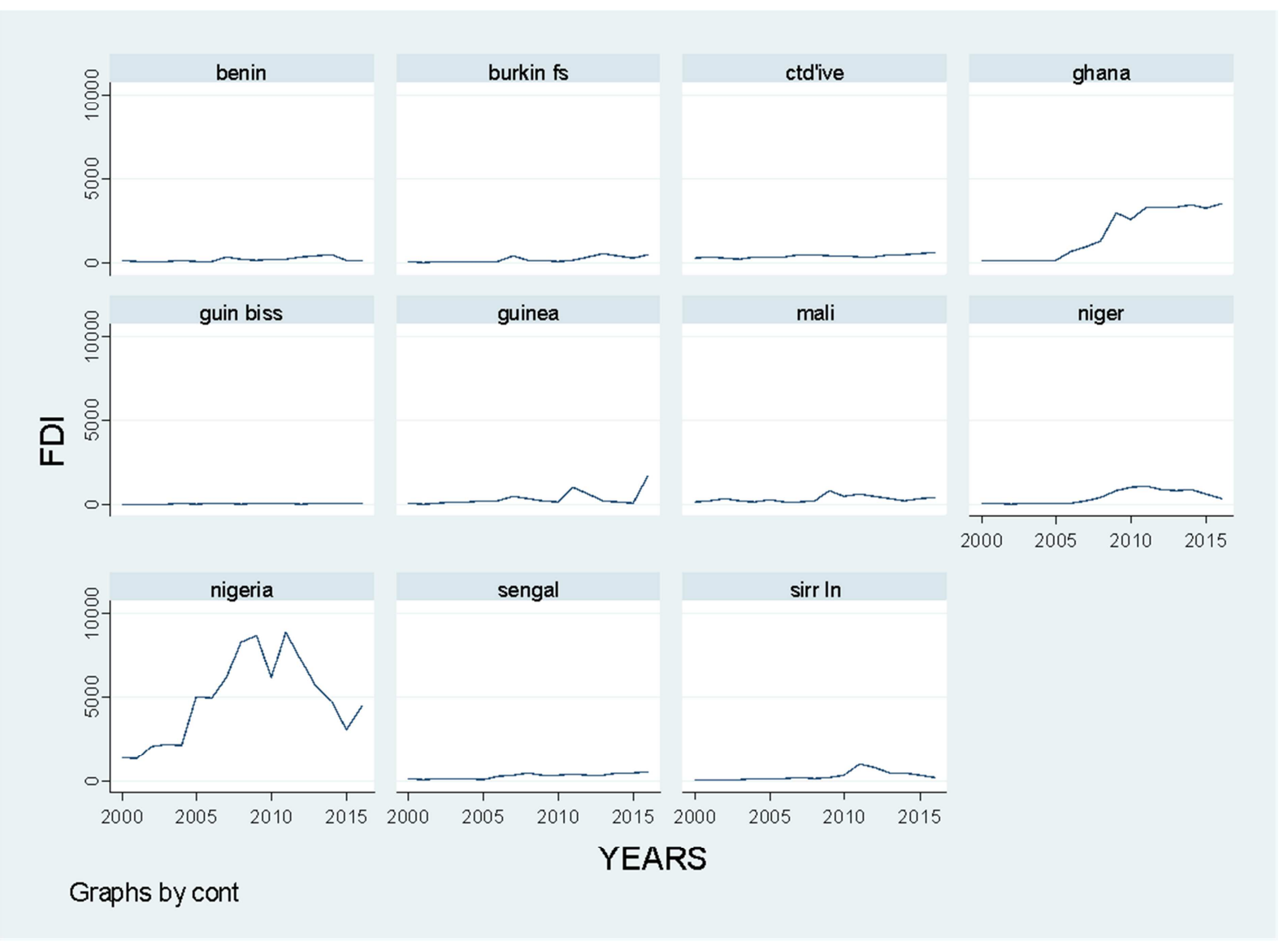

Figure 5. Panel Data line plot for FDI variable.

The Figure 5 display both the cross-sectional and time series plot of foreign direct investment over the period of time, the plot display the individual times series plot of the variables. It was observed that most of the panels (countries) display in the plot have the same movement over the years, Nigeria took an obvious exceptional with a upward and downward trend from early year to late 2016

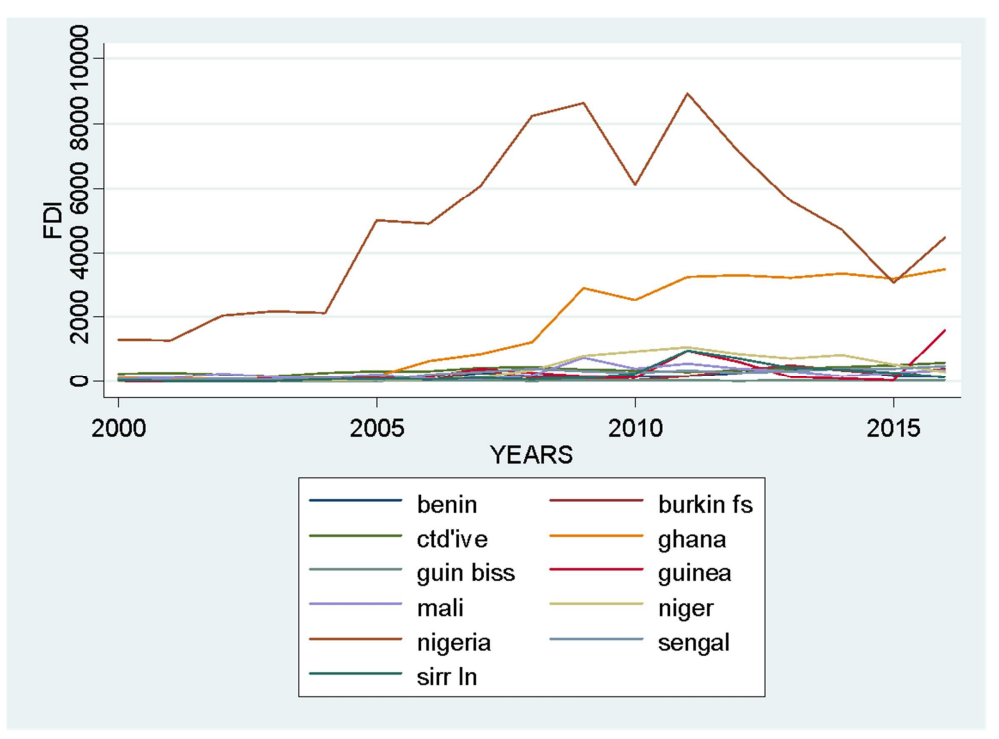

Figure 6. Overlay panel plot for FDI. 
Figure 6 display the panels plot of the countries importation within the time frame for the study, the plot is visualize in a merged and comparison point, it present the plot of different countries on one graph, it was obviously notice that Nigeria and Ghana are moving upward in their foreign direct investment, this implies that there foreign direct investment is high in compare to their counterparts in the West African sub region.

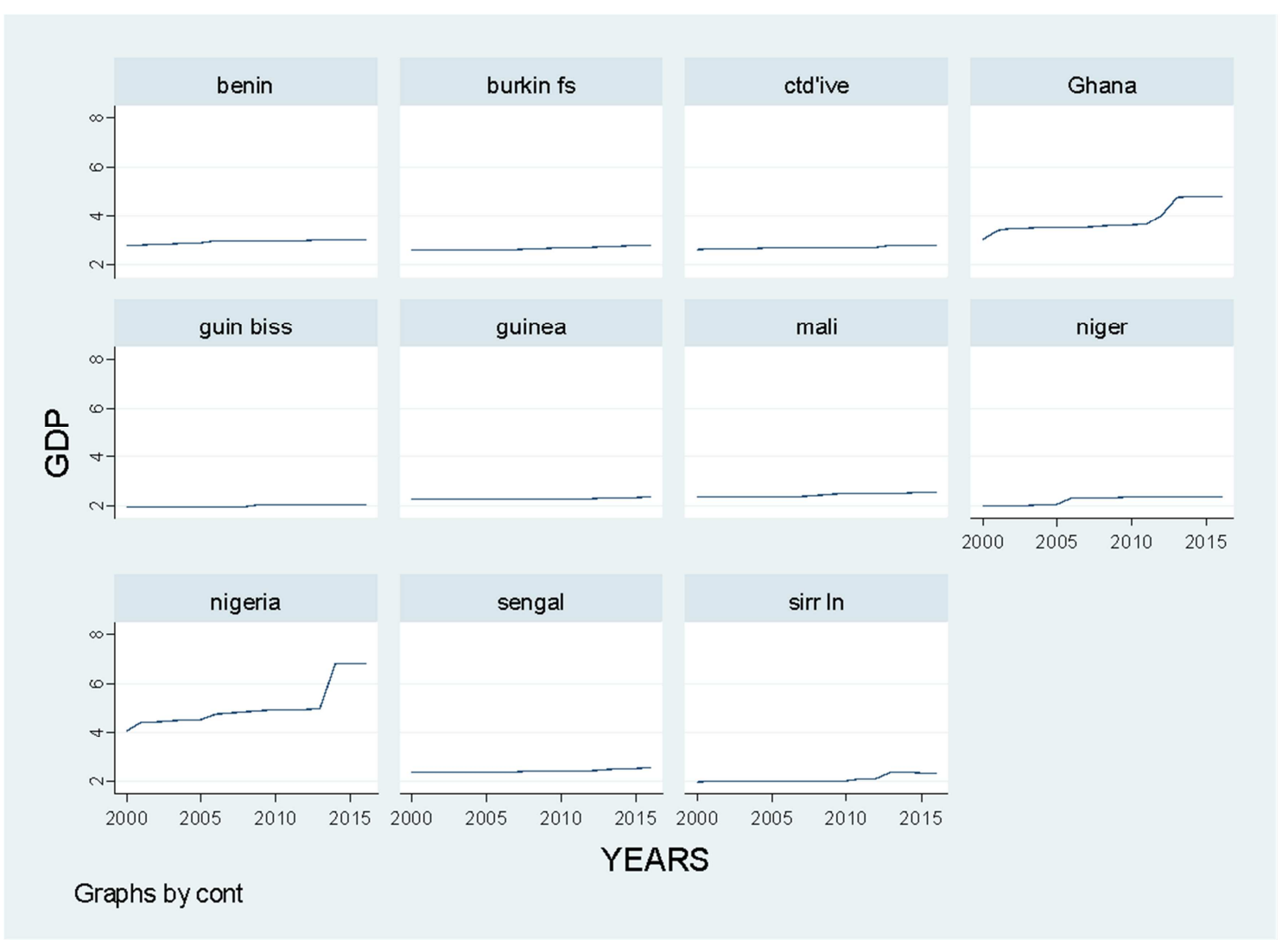

Figure 7. Panel Data line plot for GDP variable.

Figure 7, present the gross domestic production data set plot of countries under the study individual with respect to the duration, the plot display fair upward tendency in few of the countries in west African sub region while the rest of the countries follow the same pattern of movement, this implies increase in gross domestic production of some countries and slight change in the gross domestic production of other countries, this graph correspond to the decrease in the level of exportation of those countries with low or constant trend of GDP variables as observed above in the previous charts.

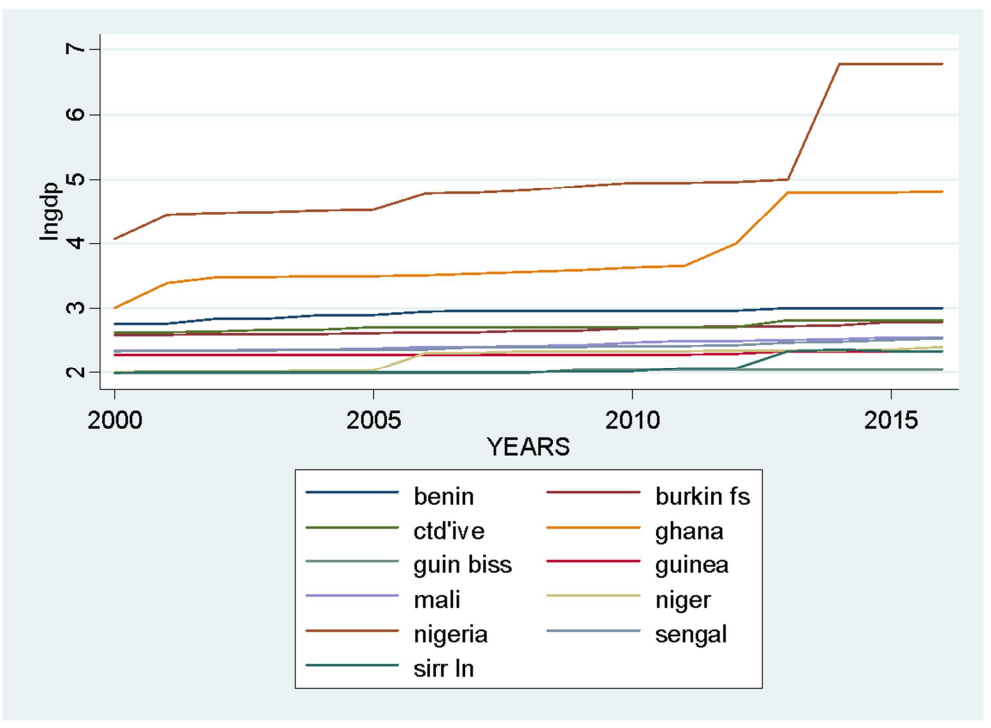

Figure 8. Overlay panel plot for GDP. 
Figure 8. display of the variables in an overlaying format which make it easier to compare the performance of the variables among the countries over the years considered, observing from the plot, it was seen that it was only Nigeria and Ghana that possess an obvious upward tendency in comparison to their counterparts in the West African sub region.

Since the plot of both export and import has been visualize, trade balance plot can be skip.

\subsection{Panel Unit Root Test Result}

Empirical work base on time series data assumes that the underlying nature of time series data is stationary. Thus, this implies that economic variables used should be stationary in nature. The unit root test is used to test the nature of time series to determine whether they are stationary or nonstationary, in order to avoid a spurious regression. Panel unit root test is the panel data (both time-series and crosssectional data) version of the time-series unit root test.

The study use non-parametric Fisher-type test which uses the Augmented Dickey Fuller (ADF) test, the null and alternative hypothesis are formulated as:

$\mathrm{H}_{0}$ : All panels contain unit roots

$\mathrm{H}_{1}$ : At least one panel is stationary

Table 3. Augmented Dickey Fuller (ADF) Unit root Test Result.

\begin{tabular}{llll}
\hline Variables & Chi-Square $\left(\chi^{\mathbf{2}}\right)$ & P-value & Remark \\
\hline LnEXP & 53.7026 & $0.0002^{*}$ & Stationary \\
LnIMP & 53.7792 & $0.0002^{*}$ & Stationary \\
LnFDI & 78.2460 & $0.0000^{*}$ & Stationary \\
LnGDP & 62.9587 & $0.0000^{*}$ & Stationary \\
TB & 57.7807 & $0.0000^{*}$ & Stationary \\
LnEXR & 83.0100 & $0.0000^{*}$ & Stationary \\
Number of panels & 10 & & \\
Number of periods & 17 & & \\
\hline
\end{tabular}

Note: $*=$ significant at $(\mathrm{p}<0.01)$

Sources: Author's Computation using STATA version 11

Table 3 presented the result of the panel unit root test of the variables; it was observed from the table that all the variables were statistically significant at I percent. Therefore, we reject the null hypothesis that states all panels contain unit roots and conclude that there are no unit roots in the panels of this study, this implies that at least one panel is stationary. The implication of this is that the variable are stationary which means that the result obtained from this study is not only possible for the present time period but can also be generalized for other periods. In addition, this means that the results obtained from this study are not spurious.

\subsection{Estimation of the Panel Data Regression Model}

This section presents the estimation of the panel regression model; the models considered in this section are pooled OLS, Random and Fixed effect model. The study observed the regression model under three different models in order to measure the linear relationship of the international trade of countries observed within the period of consideration, the models were stated out in the previous chapter.

\subsubsection{Estimation of Pooled OLS and Fixed Effect Model}

The estimation of Pooled OLS and Random effect model for the international trade panel data set of West African Sub region within the period of 16 years was display in table 4 .

The table estimates the model using pooled OLS for the ordinary least square, while fixed effect model was estimate under this section using Least Square Dummy Variable (LSDV) and within estimation technique. F-test, R-square, and SSE were use in assessing the best model and estimation technique to be used for each model under the study. The estimation was carried out in this section under three different models.

It was observed from the table 4 that under the first model were import was regress on GDP, FDI, and EXR, all the independent variable were positively significant at 1 per level significance except EXR which was positively significant at 5 percent level of significance, for both pooled OLS and the fixed effect models with coefficient value of $0.2408,0.5043$, and 0.9829 for the regressors variables (GDP, FDI, EXR) under the pooled OLS model while the coefficient value for fixed effect model are $0.1437,0.3569$, and 0.6091 for the same regressors variables under the study, which mean that one unit increase in the gross domestic production, foreign direct investment, and exchange rate will automatically lead to increase in the exportation of the study area. this implies that gross domestic production (GDP), foreign direct investment (FDI), and exchange rate (EXRT) has significance influence on importation of goods, for the countries under consideration, this was proven under the two different model used in modeling the variables. The f-test statistics of the various estimations technique were significant at 1 percent level of significance which means that null hypothesis of non-fixed effect was rejected and hence there exist fixed effect in the first model. The $\mathrm{R}^{2}$ of the fixed effect model with LSDV (0.9372) was higher than that of it counterpart fixed effect model within and pooled OLS (0.6186 and 0.8426) also the SSE of the fixed effect model (5.150) was lower than the SSE for the pooled OLS model (12.9088) which implies that fixed effect model with LSDV estimation technique is the best model for fitting the variables under the first model, Hence Fixed effect model with LSDV estimation technique perform more better than fixed effect model within and pooled OLS in the first model.

The second model in the table 4 display the model of export regressing against the same independent variables under different estimation technique, it was deduce that under pooled OLS technique all the regressors variables (GDP, FDI, EXR) were positively significant at I per cent level of significance with coefficient value $(0.2982,0.53400$, and $0.9825)$ this means that one unit increase in the regressors variables under the pooled OLS technique will increase the chance of exportation of goods in the study area which implies that GDP, FDI, EXR has significant impact on 
exportation. This result seems to be a bit contrary to fixed effect model result which was carried out under two different estimation technique, the result for the fixed effect model stated that gross domestic production (GDP) and foreign direct investment (FDI) were only the variables that are positively significant at 1 percent and 5 percent level of significance with coefficient values $(0.1029$ and 0.3832$)$, while EXR variables with coefficient value $(-0.1401)$ is negatively non-significant at 5 percent level significance, this means that one unit increase in GDP and FDI will lead to the rise of exportation in the study area and one unit increase in EXR will decrease the exportation of the study area, this implies that the only GDP and FDI has positive influence on export. From the $\mathrm{R}^{2}$, and $\mathrm{SSE}$ values for the estimation technique in the second model it was observed that fixed effect model with LSDV estimation technique has the highest R-square value of 0.955 and one of the lowest SSE value of 4.162 in comparison to pooled OLS and fixed effect model within (0.8335 and 17.0951) and (0.654 and 4.162), this implies that fixed effect model with LSDV estimation technique regressors explained the variation that occur in the dependent variable than other technique and models, since Rsquare was used to measure the goodness of fit of a model. The f-test statistics of the various estimations technique were significant at 1 percent level of significance which means that null hypothesis of non-fixed effect was rejected and hence there exist fixed effect in the second model.

From the third model in the table 4 , it was notice that under pooled OLS model only GDP was positively significant at 5 percent level of significance with coefficient value of 1411.74 while FDI is positively non-significant and EXR is negatively non-significant at 5 percent level of significance, both with coefficient value of (879.55 and 2372.59), this means that one unit increase GDP and FDI will increase the Trade Balance (TB) by 1411.74 and 879.55 while one unit increase in EXR will reduce the TB by 937.682 this implies that GDP has significance impact on trade balance (TB). Contrary to the result of the fixed effect model, all the regressors are significant at 1 per cent level of significance, but only FDI is positively significant at 1 per cent level of significance with coefficient value of 1265.48 while GDP and EXR are negatively significant at 1 percent level of significance, this result means that one unit increase in both GDP and EXR will automatically reduce the Trade Balance (TB), while one unit increase in EXR will increase the Trade Balance (TB) by 1265.48. This implies that under the third model fixed effect model deduce that only FDI has a positive significant impact on the Trade Balance of the study area. Under the criteria for assessing the performance of the model in the table the R-square value $(0.725)$ for fixed effect model with LSDV estimation technique has the highest value with lowest value of $\operatorname{SSE}\left(1.68 e^{09}\right)$ which implies the adequate efficiency of the model in comparison with pooled OLS and fixed effect model with R-square value of $(0.104$ and 0.457$)$, The f-test statistics of the various estimations technique were significant at 1 percent level of significance which means that null hypothesis of non-fixed effect was rejected and hence there exist fixed effect in the third mode.

From the three models observed in the table 4 below and the result obtained, it was notice that gross domestic production and foreign direct investment has significant effect in the effectiveness of international trade of West African sub region. It was also deduce from all the models that fixed effect model with LSDV estimation technique performs better than the other models and technique. Hence, fixed effect model with LSDV decision will be used in this section to draw a valid conclusion, the result also cover the fact that there exist fixed effect group in all the models.

Table 4. Panel Regression Result for International Trade.

\begin{tabular}{|c|c|c|c|c|c|c|c|c|c|}
\hline \multicolumn{4}{|l|}{ Model 1} & \multicolumn{3}{|l|}{ Model 2} & \multicolumn{3}{|l|}{ Model 3} \\
\hline \multicolumn{4}{|c|}{ Dependent variable: Import } & \multicolumn{3}{|c|}{ Dependent variable: Export } & \multicolumn{3}{|c|}{ Dependent variable: Trade Bal. } \\
\hline Variables & Pooled OLS & Within & LSDV & Pooled OLS & Within & LSDV & Pooled OLS & Within & LSDV \\
\hline Lngdp & $\begin{array}{l}0.2408^{*} \\
(.000)\end{array}$ & $\begin{array}{l}0.1437^{*} \\
(.001)\end{array}$ & $\begin{array}{l}0.1437^{*} \\
(.001)\end{array}$ & $\begin{array}{l}0.2982^{*} \\
(.000)\end{array}$ & $\begin{array}{l}0.1029^{* *} \\
(.011)\end{array}$ & $\begin{array}{l}0.1029^{* *} \\
(.011)\end{array}$ & $\begin{array}{l}1411.74^{* *} \\
(0.020)\end{array}$ & $\begin{array}{l}-9000.13^{*} \\
(0.000)\end{array}$ & $\begin{array}{l}-9000.13^{*} \\
(0.000)\end{array}$ \\
\hline Lnfdi & $\begin{array}{l}0.5043^{*} \\
(.000)\end{array}$ & $\begin{array}{l}0.3569^{*} \\
(.000)\end{array}$ & $\begin{array}{l}0.3569^{*} \\
(.000)\end{array}$ & $\begin{array}{l}0.53400^{*} \\
(.000)\end{array}$ & $\begin{array}{l}0.3832^{*} \\
(.001)\end{array}$ & $\begin{array}{l}0.3832^{*} \\
(.001)\end{array}$ & $\begin{array}{l}879.55 \\
(0.188)\end{array}$ & $\begin{array}{l}1265.48^{*} \\
(0.005)\end{array}$ & $\begin{array}{l}1265.48^{*} \\
(0.005)\end{array}$ \\
\hline Lnexr & $\begin{array}{l}0.9829^{*} \\
(.000)\end{array}$ & $\begin{array}{l}0.6091^{* *} \\
(.021)\end{array}$ & $\begin{array}{l}0.6091^{* *} \\
(.021)\end{array}$ & $\begin{array}{l}0.9825^{*} \\
(.000)\end{array}$ & $\begin{array}{l}-.1401 \\
(.571)\end{array}$ & $\begin{array}{l}-.1401 \\
(.571)\end{array}$ & $\begin{array}{l}-2372.59 \\
(0.601)\end{array}$ & $\begin{array}{l}-1354.88^{*} \\
(0.000)\end{array}$ & $\begin{array}{l}-1354.88^{*} \\
(0.000)\end{array}$ \\
\hline Constant & $\begin{array}{l}-.3142 \\
(.468)\end{array}$ & $\begin{array}{l}1.0271 \\
(.056)\end{array}$ & $\begin{array}{l}0.8718 \\
(.119)\end{array}$ & $\begin{array}{l}-0.7008 \\
(.160)\end{array}$ & $\begin{array}{l}2.4132^{*} \\
(.000)\end{array}$ & $\begin{array}{l}2.2605 \\
(.000)\end{array}$ & $\begin{array}{l}-937.682 \\
(0.916)\end{array}$ & $\begin{array}{l}49426.55^{*} \\
(0.000)\end{array}$ & $\begin{array}{l}508.60^{*} \\
(0.000)\end{array}$ \\
\hline $\begin{array}{l}\text { Country } \\
\text { (Dummy) }\end{array}$ & & & & & & & & & \\
\hline 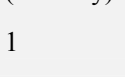 & & & $\begin{array}{l}0.1628^{* *} \\
(0.01)\end{array}$ & & & $\begin{array}{l}0.700 \\
(0.239)\end{array}$ & & & $\begin{array}{l}-3151.8^{*} \\
(0.006)\end{array}$ \\
\hline 2 & & & $\begin{array}{l}0.5599^{*} \\
(.000)\end{array}$ & & & $\begin{array}{l}0.773^{*} \\
(.000)\end{array}$ & & & $\begin{array}{l}-1233.73 \\
(0.287)\end{array}$ \\
\hline 6 & & & $\begin{array}{l}-.0026 \\
(.968) \\
0.1081 \\
(.097)\end{array}$ & & & $\begin{array}{l}.096 \\
(.129) \\
0.161^{*} \\
(.001)\end{array}$ & & & $\begin{array}{l}-4798.24^{*} \\
(0.000) \\
-5476.59^{*} \\
(0.000)\end{array}$ \\
\hline
\end{tabular}




\begin{tabular}{|c|c|c|c|c|c|c|c|c|c|}
\hline \multicolumn{4}{|l|}{ Model 1} & \multicolumn{3}{|l|}{ Model 2} & \multicolumn{3}{|l|}{ Model 3} \\
\hline \multicolumn{4}{|c|}{ Dependent variable: Import } & \multicolumn{3}{|c|}{ Dependent variable: Export } & \multicolumn{3}{|c|}{ Dependent variable: Trade Bal. } \\
\hline Variables & Pooled OLS & Within & LSDV & Pooled OLS & Within & LSDV & Pooled OLS & Within & LSDV \\
\hline 7 & & & $\begin{array}{l}.0731^{*} \\
(.000)\end{array}$ & & & $\begin{array}{l}-0.148^{* *} \\
(.026)\end{array}$ & & & $\begin{array}{l}-7643.78^{*} \\
(0.000)\end{array}$ \\
\hline 8 & & & $\begin{array}{l}0.5708^{*} \\
(.000)\end{array}$ & & & $\begin{array}{l}0.909^{*} \\
(.000)\end{array}$ & & & $\begin{array}{l}29709.12^{*} \\
(0.000)\end{array}$ \\
\hline 9 & & & $\begin{array}{l}0.4199^{*} \\
(.000)\end{array}$ & & & $\begin{array}{l}0.318^{*} \\
(.000)\end{array}$ & & & $\begin{array}{l}-7696.36^{*} \\
(0.000)\end{array}$ \\
\hline F-test & $\begin{array}{l}326.54^{*} \\
(.000)\end{array}$ & $\begin{array}{l}93.33^{*} \\
(.000)\end{array}$ & $\begin{array}{l}198.58^{*} \\
(.000)\end{array}$ & $\begin{array}{l}305.39^{*} \\
(.000)\end{array}$ & $\begin{array}{l}108.92^{*} \\
(.000)\end{array}$ & $\begin{array}{l}282.98^{*} \\
(.000)\end{array}$ & $\begin{array}{l}7.081^{*} \\
(0.005)\end{array}$ & $\begin{array}{l}48.43^{*} \\
(0.000)\end{array}$ & $\begin{array}{l}35.09^{*} \\
(0.000)\end{array}$ \\
\hline $\mathrm{R}^{2}$ & 0.8426 & 0.6186 & 0.9372 & 0.8335 & 0.654 & 0.955 & 0.104 & 0.457 & 0.725 \\
\hline SSE & 12.9088 & 5.1507 & 5.150 & 17.0951 & 4.612 & 4.162 & $5.47 e^{09}$ & $1.68 e^{09}$ & $1.68 e^{09}$ \\
\hline $\mathrm{N}$ & 187 & 187 & 187 & 187 & 187 & 187 & 187 & 187 & 187 \\
\hline
\end{tabular}

Note: $* *=$ significant at $(\mathrm{p}<0.05), *=$ significant at $(\mathrm{p}<0.01)$

\subsubsection{Estimation of Pooled OLS and Random Effect Model}

This section presents the estimation of the panel data regression analysis for the three model considered in the study under random effect model in comparison with pooled OLS having believe that differences across the entities considered in the study (country) have some influence on the dependent variable for the three models. Unlike the fixed effect model, the variation across entities is assumed to be random and uncorrelated with the predictors or independent variables included in the model.

From the previous estimation the pooled OLS model has been well explained, the table 5 display the comparison of the Pooled OLS and Random Effect model for the data set, it was observed form the table that the random effect estimation for the first model show that the two tail p-values test the hypothesis that each coefficient is different from 0 , the null hypothesis is rejected at $1 \%$ level of significance showing that all the independent variables under the first model (GDP, FDI, EXR) were positively significant at $1 \%$ level of significance with coefficient value of $(0.20183,0.37003$, and $0.7144)$, which means that one unit increase in all the regressor variables will raise the percentage of importation over the study area. this implies that importation of goods is influence by the gross domestic production, foreign direct investment and exchange rate. The R-square value of the random effect model regressors explained $61 \%$ variation that exist in the dependent variable and the Wald test is significant at $(\mathrm{p}<0.01)$ showing that the random effect model is adequate, finally the Breusch -Pagan LM test for random effect model was tested in the analysis and the null hypothesis of $\operatorname{Var}(\mathrm{u})=0$ was rejected at $(\mathrm{p}<0.000)$ which implies that there is a significant random effect in the panel data, and that the random effect model is able to deal with heterogeneity better than the pooled OLS in the first model.

The second model in the table 5 display the model of export regressing against the same independent variables under random effect model and Pooled OLS, having considered the detail interpretation of Pooled OLS for the second model in the previous section much attention will be pay to interpret the random effect model. It was deduce that under random effect model technique the regressors variables (GDP and FDI) were positively significant at I per cent level of significance with coefficient value (0.51989 and 0.39044$)$ this means that one unit increase in the regressors variables (GDP and FDI) under the random effect technique will increase the exportation in study area which implies that GDP and FDI has significant impact on exportation, while exchange rate is positively non-significant that one unit increase in exchange rate will increase export by 0.0044 , From the $\mathrm{R}^{2}$, and SSE values for the estimation technique in the second model it was observed that random effect model has R-square value of 0.6503 which explain the degree of variation that occur in the dependent variable by $65 \%$, with SSE value of 5.724 which is lower than that of pooled OLS model (17.0951). The Wald test is also significant at $1 \%$ level of significance for the second model. Finally the Breusch Pagan LM test for random effect model was tested in the analysis and the null hypothesis of $\operatorname{Var}(\mathrm{u})=0$ was rejected at $(\mathrm{p}<0.000)$ which implies that there is a significant random effect in the panel data, and that the random effect model is able to deal with heterogeneity better than the pooled OLS in the second model.

It was observed from the third model in the table 5 below that only foreign direct investment (FDI) was positively significant at $5 \%$ level of significance with coefficient value of 1311.033 which means that one unit increase in FDI will increase the trade balance across the entities by 1311.033, while GDP is negatively significant at $1 \%$ level of significance that is one unit increase in GDP will reduce the trade balance by 6083.125 and EXR is negatively nonsignificant at $5 \%$ level of significance, this results implies that Trade balance (TB) is only positively influence by foreign direct investment (FDI), the result is different from the result in under the pooled OLS estimation technique, detail interpretation on the pooled OLS has stated in the previous section. The $\mathrm{R}^{2}$ value for the random effect model pigged $44 \%$ which implies $44 \%$ explanation of variation that exist in the dependent variable from the regressor with SSE of $3.135 e^{08}$ which is lower than the pooled OLS model. The Wald test was also significant at $1 \%$ level of significance in the third model which implies the accuracy of the model. And finally the Breusch -Pagan LM test for random effect model was tested in the analysis and the null hypothesis of $\operatorname{Var}(\mathrm{u})=0$ was rejected at $(\mathrm{p}<0.000)$ which implies that there is a significant random effect in the panel data, and that the 
random effect model is able to deal with heterogeneity better than the pooled OLS in the third model.

Table 5. Panel Regression Result for International Trade (Random Effect Model).

\begin{tabular}{|c|c|c|c|c|c|c|}
\hline \multicolumn{3}{|l|}{ Model 1} & \multicolumn{2}{|c|}{ Model 2} & \multicolumn{2}{|c|}{ Model 3} \\
\hline \multicolumn{3}{|c|}{ Dependent variable: Import } & \multicolumn{2}{|c|}{ Dependent variable: Export } & \multicolumn{2}{|c|}{ Dependent variable: Trade Bal. } \\
\hline Variables & Pooled OLS & Random Effect & Pooled OLS & Random Effect & Pooled OLS & Random Effect \\
\hline Lngdp & $\begin{array}{l}0.2408^{* *} \\
(0.000)\end{array}$ & $\begin{array}{l}0.20183 * * \\
(0.000)\end{array}$ & $\begin{array}{l}0.2982 * * \\
(0.000)\end{array}$ & $\begin{array}{l}0.51989 * * \\
(0.000)\end{array}$ & $\begin{array}{l}1411.74 * \\
(0.020)\end{array}$ & $\begin{array}{l}-6083.125^{* *} \\
(0.000)\end{array}$ \\
\hline Lnfdi & $\begin{array}{l}0.5043^{* *} \\
(0.000)\end{array}$ & $\begin{array}{l}0.37003^{* *} \\
(0.000)\end{array}$ & $\begin{array}{l}0.53400^{* *} \\
(0.000)\end{array}$ & $\begin{array}{l}0.39044 * * \\
(0.000)\end{array}$ & $\begin{array}{l}879.55 \\
(0.188)\end{array}$ & $\begin{array}{l}1311.033^{*} \\
(0.012)\end{array}$ \\
\hline Lnexr & $\begin{array}{l}0.9829^{* *} \\
(0.000)\end{array}$ & $\begin{array}{l}0.71444 * * \\
(0.005)\end{array}$ & $\begin{array}{l}0.9825^{* *} \\
(0.000)\end{array}$ & $\begin{array}{l}0.0044 \\
(0.986)\end{array}$ & $\begin{array}{l}-2372.59 \\
(0.601)\end{array}$ & $\begin{array}{l}-9891.993 \\
(0.057)\end{array}$ \\
\hline Constant & $\begin{array}{l}-0.3142 \\
(0.468)\end{array}$ & $\begin{array}{l}0.62729 \\
(0.5724)\end{array}$ & $\begin{array}{l}-0.7008 \\
(0.160)\end{array}$ & $\begin{array}{l}1.95089^{* *} \\
(0.000)\end{array}$ & $\begin{array}{l}-937.682 \\
(0.916)\end{array}$ & $\begin{array}{l}33936.45 * * \\
(0.001)\end{array}$ \\
\hline F, Wald-Test & $\begin{array}{l}326.54^{* *} \\
(0.000)\end{array}$ & $\begin{array}{l}357.44 * * \\
(0.000)\end{array}$ & $\begin{array}{l}305.39 * * \\
(0.000)\end{array}$ & $\begin{array}{l}355.95 * * \\
(0.000)\end{array}$ & $\begin{array}{l}7.081 * * \\
(0.005)\end{array}$ & $\begin{array}{l}63.95 * * \\
(0.000)\end{array}$ \\
\hline SSE & 0.8426 & 6.1371 & 17.0951 & 5.724 & $5.47 e^{08}$ & $3.135 e^{08}$ \\
\hline $\mathrm{R}^{2}$ & 12.9088 & 0.6161 & 0.8333 & 0.6503 & 0.104 & 0.4487 \\
\hline $\begin{array}{l}\mathrm{N} \\
\text { LM-Test }\left(\chi^{2}\right)\end{array}$ & 187 & $\begin{array}{l}187 \\
286.84^{* *} \\
(0.000)\end{array}$ & 187 & $\begin{array}{l}187 \\
408.29 * * \\
(0.000)\end{array}$ & 187 & $\begin{array}{l}187 \\
127.74 * * \\
(0.000)\end{array}$ \\
\hline
\end{tabular}

Note: $* *=$ significant at $\mathrm{p}<0.01, *=$ significant at $\mathrm{p}<0.05$

Sources: Author's Computation using STATA version 11

Therefore having considered the three model under random effect technique, hence we conclude that international trade is influences positively by Gross Domestic Production (GDP) and Foreign Direct Investment (FDI), also there exist random effect in the model which was conclude from the Breuch-Pagan (LM) test observed in the three models.

\subsection{Hausman Test Result}

Having considered the result form the two previous tables on the models under consideration, it was deduce from the three models that fixed effect technique and random effect technique perform better than pooled OLS. In order to verify which of the technique to use between the fixed effect and random effect technique, the two techniques were subjected to Hausman test for the three models to ensure that the models are devoid of any correlated random cross-sectional effects. The underlying hypothesis formulated in order to determine whether to use Fixed Effect or Random Effect is specified as:

$\mathrm{H}_{0}: \operatorname{var}(b)=\operatorname{var}(B)$ there is no correlated random effect $\mathrm{H}_{1}: \operatorname{var}(b) \neq \operatorname{var}(B)$ there is correlated random effect

Var (b) and Var (B) refer to the variances of the fixed effect and random effect respectively. The null hypothesis states that there is no correlated random effect which suggests that random effect estimates are better than those of fixed effect; while the alternative hypothesis states that there is correlated random effect which suggests that fixed effect estimates are better than those of random effect in this study.

Table 6. Hausman Specification Test.

\begin{tabular}{llllllllll}
\hline \multicolumn{2}{l}{ Model 1 } & \multicolumn{4}{c}{ Model 2 } & \multicolumn{3}{l}{ Model 3 } \\
\hline \multicolumn{2}{l}{ Coefficients } & & \multicolumn{3}{c}{ Coefficients } & \multicolumn{3}{c}{ Coefficients } \\
\hline Variables & (b) RE & (B) FE & (b-B) Differences & (b) RE & (B) FE & (b-B) Differences & (b) RE & (B) FE & (b-B) Differences \\
\hline Lngdp & 0.201827 & 0.143738 & 0.058089 & 0.159891 & 0.102972 & 0.056919 & -6083.13 & -9000.13 & 2917.004 \\
Lnfdi & 0.370038 & 0.356954 & 0.013084 & 0.390449 & 0.383252 & 0.007198 & 1311.033 & 1265.416 & 45.61642 \\
Lnexr & 0.714447 & 0.609161 & 0.105286 & 0.004448 & -0.14017 & 0.14462 & -9891.99 & -13542.9 & 3650.892 \\
$\chi^{2}$ & 7.96 & & & 27.66 & & & 13418.10 & & \\
\hline
\end{tabular}

Sources: Author's Computation using STATA version 11

The estimate of the Hausman test for the three models of chi-sq test statistics $(7.96,27.66$, and 13418.10) are less than the chi-sq tabulate (7.815) at 5\% level of significance with $\mathrm{df}$ (3), this means that the null hypothesis of no correlated random effect were rejected for the three models and the alternative hypothesis accepted. This implies that fixed effect model result were more efficient than that of the random effect models as seen in table 6 . Hence, we then adopt the results from the fixed effect model as basis for the interpretation of the relationship between the dependent variable and independent variables in the models considered for the study.

\section{Conclusion}

The study divided the models into three in other to have proper view of factors influencing international trade across West African Sub-region, each model contain the same independent variables and different dependent variables. The study carried out preliminary analysis on the panel data set 
before fitting in the models. Also Panel Unit Root analysis was carried out on each of the variables to test the stationarity of the data set across the entities (country). The study then adopt Pooled OLS, Fixed Effect Model, and Random Effect Model to fit the panel regression model for the panel data sets, F-test was use to select between Pooled OLS model and Fixed effect model, Breush-Pagan LM test was use to known the best model between Pooled OLS and Random effect model, and finally Hausman specification test was used to decide between fixed effect model and random effect model. The result shows that fixed effect model was accurate for the study. Also from the study it was observed that for the first model which use import as dependent variable, gross domestic production, foreign direct investment, and exchange rate are positively significant to import which implies that all the regressor variable influence import across west African sub region positively, while only GDP and FDI are positively significant to export and only FDI is positively significant to trade balance (TB). We therefore conclude that foreign direct investment is the key macro-economic variable that positively influences the policy of international trade across West African over the period of consideration.

\section{References}

[1] Posner, M. V. 1961. 'International Trade and Technical Changes', Oxford Economic Papers, No. 13: 323-341.

[2] Vernon, R. 1966. 'International Investment and International Trade in the Product Cycle' Quarterly Journal of Economics, No. 80: 190-207.

[3] Dreze, J. 1961. 'Leo Exportation Intra-CEE en 1958 et al Position Belge', RecherchesEconomiques de Louvain (louvin), 27, 7171-738.

[4] Mathur, S. K. 1999. 'Pattern of International Trade, New Trade Theories and Evidence from Gravity Equation Analysis', The Indian Economic Journal, Vol. 47, No. 4: 68-88.

[5] Paas, T. 2000. 'Gravity Approach for Modeling Trade Flows between Estonia and the Main Trading Partners', Working Paper, No. 721, Tartu University Press, Tartu.

[6] Rodríguez, Francisco and Dani Rodrik. 2001. "Trade Policy and Economic Growth: A Skeptic's Guide to the CrossNational Evidence," in Ben Bernanke and Kenneth S. Rogoff, eds., Macroeconomics Annual 2000, Cambridge, MA: MIT Press for NBER.

[7] Sachs, Jeffrey D. and Andrew Warner. 1995. "Economic
Reform and the Process of Global Integration.” Brookings Papers on Economic Activity 1: 1-118.

[8] Frankel, Jeffrey and David Romer. 1999. "Does Trade Cause Growth?” American Economic Review 89 (June): 379-99

[9] Vamvakidis, Athanasios. 2002. "How Robust Is the GrowthOpenness Connection? Historical Evidence." Journal of Economic Growth 7: 57-80.

[10] World Bank, 2016, 2012. World Development Indicators (WDI). Economic and Social Data Service 665 (ESDS) International, (Mimas) University of Manchester

[11] Musila, J. W., Sigué, S. P. and Anyangah, J. O. (2003) "An assessment of currency depreciation on inflation in Malawi: simulation results from a macroeconometric model,", The Journal of African Development, Vol. 6, pp. 78-113.

[12] McAleese, D. (2004) Economics for business: competition, macrostability and globalisation. 3rd ed. Edinburgh Gate: Pearson Education Limited

[13] Borensztein, E., J. De Gregoria and J. Lee. 1998. "How does foreign investment affect economic growth?" Journal of International Economics, 45 (1): 115-35

[14] Collier, P. and Dollar, D. (2001) "Development effectiveness: What have we learnt"? Development Research Group, the World Bank. Available online at http://www.oecd.org/dataoecd/16/2/2664872.pdf. Accessed on 20/10/2010

[15] Hare, R. D. (2006). Psychopathy: A clinical and forensic overview. Psychiatric Clinics of North America, 29 (3), 709724.

[16] Dollar, D. and A. Kraay (2003) 'Institutions, Trade, and Growth', Journal of Monetary Economics, 50: 133-62.

[17] Baltagi, B. H. and Y. J. Chang, 1994, Incomplete panels: A comparative study of alternative estimators for the unbalanced one-way error component regression model, Journal of Econometrics 62, 67-89.

[18] Greene, W. H. (2008) Econometric Analysis. 6th Edition, Pearson Prentice Hall, Upper Saddle River.

[19] Breusch, T. S. and A. R. Pagan, 1980, The Lagrange multiplier test and its applications to model specification in econometrics, Review of Economic Studies 47, 239-253.

[20] Hausman, J. (1978), Specification Tests in Econometrics. Econometrica, Vol. 46, nº, pp. 1251-1271.

[21] Baltagi, B. H. (2001). Econometric Analysis of Panel Data. John Wiley and Sons, New York, 2nd ed.

[22] Kennedy, Peter. 2008. A Guide to Econometrics, 6th ed. Malden, MA: Blackwell Publishing. 